\title{
Effect of Duration of Fixation on Quantitative Reverse Transcription Polymerase Chain Reaction Analyses
}

\author{
Maricris Macabeo-Ong, B.S., David G. Ginzinger, Ph.D., Nusi Dekker, M.A., Alex McMillan, Ph.D., \\ Joseph A. Regezi, D.D.S., David T.W. Wong, D.MSc., Richard C.K. Jordan, D.D.S., Ph.D. \\ Oral Pathology, Department of Stomatology (MM-O, ND, JAR, RCKJ); Department of Pathology (JAR, \\ RCKJ), University of California San Francisco, San Francisco; UCSF Cancer Center (RCKJ, DGG), San \\ Francisco; Dental Research Institute, UCLA (DTWW), Los Angeles, California
}

Increasingly, there is the need to analyze gene expression in tumor tissues and correlate these findings with clinical outcome. Because there are few tissue banks containing enough frozen material suitable for large-scale genetic analyses, methods to isolate and quantify messenger RNA (mRNA) from formalin-fixed, paraffin-embedded tissue sections are needed. Recovery of RNA from routinely processed biopsies and quantification by the polymerase chain reaction (PCR) has been reported; however, the effects of formalin fixation have not been well studied. We used a proteinase K-salt precipitation RNA isolation protocol followed by TaqMan quantitative PCR to compare the effect of formalin fixation for 24, 48, and 72 hours and for 1 week in normal (2), oral epithelial dysplasia (3), and oral squamous cell carcinoma (4) specimens yielding 9 fresh and 36 formalin-fixed samples. We also compared mRNA and protein expression levels using immunohistochemistry for epidermal growth factor receptor (EGFR), matrix metalloproteinase (MMP)-1, p21, and vascular endothelial growth factor (VEGF) in 15 randomly selected and routinely processed oral carcinomas. We were able to extract RNA suitable for quantitative reverse transcription (RT) from all fresh (9/9) and formalinfixed (36/36) specimens fixed for differing lengths of time and from all $(15 / 15)$ randomly selected oral squamous cell carcinoma. We found that prolonged formalin fixation ( $>48 \mathrm{~h}$ ) had a detrimen-

Copyright (C) 2001 by The United States and Canadian Academy of Pathology, Inc.

VOL. 15, NO. 9, P. 979, 2001 Printed in the U.S.A.

Date of acceptance: May 13, 2002.

Supported by the following: University of California San Francisco (UCSF) Simon Fund/Research Evaluation Allocation Committee, University of California Academic Senate, UCSF/American Cancer Society; National Institutes of Health (NIH)/NIDCR Grant PO1DE13904; and NIH/National Cancer Institute Grant CA095231.

Address reprint requests to: Richard Jordan, D.D.S., Ph.D., Rm. S-512, University of California San Francisco, 513 Parnassus Avenue, San Francisco, CA 94143-0424; e-mail: rckj@itsa.ucsf.edu; fax: 415-476-6482.

DOI: 10.1097/01.MP.0000026054.62220.FC tal effect on quantitative RT polymerase chain reaction results that was most marked for MMP-1 and VEGF but less evident for p21 and EGFR. Comparisons of quantitative RT polymerase chain reaction and immunohistochemistry showed that for all markers, except p21, there was good correlation between mRNA and protein levels. p21 mRNA was overexpressed in only one case, but protein levels were elevated in all but one tumor, consistent with the established translational regulation of p21. These results show that RNA can be reliably isolated from formalin-fixed, paraffinembedded tissue sections and can produce reliable quantitative RT-PCR data. However, results for some markers are adversely affected by prolonged formalin fixation times.

KEY WORDS: Cancer, Fixation, Formalin, PCR, Quantification, Real time, Reverse transcription. Mod Pathol 2001;15(9):979-987

A number of methods are available to analyze messenger RNA (mRNA) expression in tissues including Northern hybridization, subtractive hybridization, RNase protection assay, mRNA differential display, and CDNA microarrays. All have the potential to characterize differentially expressed genes providing new insights into the biology of many diseases. However, these methods are significantly limited by the requirement for fresh, unfixed tissues to permit isolation of abundant, high-quality mRNA.

Although many institutions are building frozen tissue banks, few are at the stage to permit largescale genetic analyses or to have sufficiently longterm follow-up to yield meaningful clinical data. By contrast, there is a vast supply of archived formalinfixed, paraffin-embedded tissue blocks, often with long patient follow-up and outcome data (1). The ability to predictably recover sufficient RNA for cDNA template generation and subsequent quantitative polymerase chain reaction (PCR) thus offers tremendous potential in the study of a myriad of 
diseases. Potentially, quantitative PCR offers a number of advantages over traditional methods because it permits the use of relatively small amounts of genetic material that may be fragmented or degraded, such as that obtained from routinely processed tissue sections (2).

Recent studies have demonstrated that RNA can be extracted from formalin-fixed, paraffin-embedded tissue sections, converted to cDNA, and then subjected to quantitative PCR $(3,4)$. Comparisons of fresh and fixed tissues using quantitative PCR methods have shown that mRNA expression levels are similar, supporting the validity of this method for analysis of gene expression in fixed tissues (5). Some studies have examined the effect of differing formalin fixation times ranging from 12 to 24 hours and have found that formalin fixation does not adversely affect the quality of RNA that is destined for PCR analysis (6-9). These short fixation times may be applicable to small biopsies collected in hospital settings but likely do not reflect the more typical prolonged fixation times that are used for larger specimens or those collected in outpatient settings. Therefore, the objective of this study was to assess the effect of prolonged formalin fixation on the suitability of mRNA for quantification using the real-time TaqMan PCR assay.

\section{MATERIALS AND METHODS}

\section{Tissue Collection and Processing}

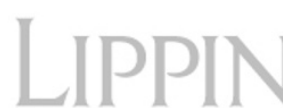

For testing of the effect of differing fixation times on tissues for quantitative reverse transcription polymerase chain reaction (RT-PCR), biopsies of normal oral mucosa $(n=2)$, oral epithelial dysplasia $(n=3)$, and oral squamous cell carcinoma $(n=$ 4) were obtained from the Oral Cancer Research Center tissue bank at the University of California San Francisco. All tissues had been obtained at the time of surgical excision, immediately snap frozen in liquid nitrogen, and stored at $-70^{\circ} \mathrm{C}$. Each sample was then thawed briefly and divided by scalpel into five similarly sized pieces. To minimize contamination, a new scalpel was used for each specimen. To ensure proper and rapid fixation, all tissue pieces were sectioned to ensure that all spatial dimensions were $\leq 5 \mathrm{~mm}(5 \times 5 \times 5 \mathrm{~mm})$. One piece (0-h sample) was placed in RLT buffer from the Qiagen RNA extraction kit (Qiagen Inc., Valencia, CA). The other four pieces were immediately placed in $10 \mathrm{~mL}$ of $10 \%$ buffered formalin and fixed for 24 , 48, and 72 hours and for 1 week. After formalin fixation, samples were dehydrated, incubated in xylene, and then embedded in paraffin using a Leica Paraffin Embedder (Leica Microsystems Inc., Deerfield, IL). There were a total of 9 fresh samples and 36 formalin-fixed specimens. All diagnoses were confirmed by examination of $5-\mu \mathrm{m}$ hematoxylin and eosin-stained sections to ensure that all tissues were similarly representative.

To compare mRNA and protein expression, we used routinely processed paraffin sections of 15 oral squamous cell carcinoma obtained from the tissue bank. All specimens were similarly sized and had been immediately fixed in $10 \%$ neutral buffered formalin for 24 hours before being processed to paraffin as described above.

\section{RNA Isolation from Fresh Tissues}

RNA was isolated from fresh tissues using the Qiagen RNeasy Total RNA System (Qiagen Inc.) according to the manufacturer's protocol. RNA was resuspended in $100 \mu \mathrm{L}$ of RNase-free water. RNAs were quantified by spectrophotometer at OD of 260 $\mathrm{nm}$, and A260/A280 ratios $\geq 1.8$ were considered high purity (5).

\section{RNA Isolation from Fixed Tissues}

Total RNA was isolated from $4 \times 10-\mu \mathrm{m}$ paraffin sections using modifications to the Paraffin Block RNA Isolation kit (Ambion Corp., Austin, TX). Briefly, sections were microtome cut from paraffintissue samples onto clean glass microscope slides. The microtome was cleaned after each use, and the tissue sections floated in a water bath containing DEPC-treated water before being mounted on glass slides. Sections were deparaffinized three times in xylene for 5 minutes each, followed by one wash with $100 \%$ ethanol for 5 minutes. The sections were then scraped off the glass slides using a clean razor blade and placed in $105 \mu \mathrm{L}$ of RNA lysis buffer containing $500 \mu \mathrm{g} / \mathrm{mL}$ of proteinase K. Sections were then incubated for 18 hours, at $56^{\circ} \mathrm{C}$, until the tissues were solubilized. RNA was obtained by extraction with an equal volume of $70 \%$ phenol $(\mathrm{pH}$ 4.3):30\% chloroform at room temperature. Samples were centrifuged for 5 minutes at $15,000 \mathrm{rpm}$ and the aqueous phase transferred to new, RNase-free Eppendorf tubes. The RNA was precipitated by the addition of an equal volume of isopropanol and 1 $\mu \mathrm{g}$ of linear acrylamide for 2 hours at $-20^{\circ} \mathrm{C}$. The samples were then centrifuged for 15 minutes at $14,000 \mathrm{rpm}$, and the pellets washed in $70 \%$ ethanol, air dried on the bench top, and then resuspended in $50 \mu \mathrm{L}$ of RNase-free water. Ten microliters of extracted RNA was then treated with $1 \mu \mathrm{L}$ DNase I $(2 \mathrm{U} / \mu \mathrm{L})$ in $2 \mu \mathrm{L}$ of $10 \times$ DNase I Reaction Buffer and $7 \mu \mathrm{L}$ of Nuclease-free water and incubated for 15 minutes at $37^{\circ} \mathrm{C}$. RNA was then extracted with acid phenol-chloroform and precipitated by adding 1 $\mu \mathrm{L}$ of linear acrylamide $(5 \mathrm{mg} / \mathrm{mL}) ; 10 \mu \mathrm{L}$ of $3 \mathrm{M}$ sodium acetate, $\mathrm{pH} 4.5$; and one volume of isopropanol, incubated in $-20^{\circ} \mathrm{C}$ for 30 minutes and 
resuspended in $50 \mu \mathrm{L}$ of RNase-free water as the final volume.

\section{Reverse Transcription}

RT was performed using Gibco BRL Reverse Transcription kit (Life Technologies, Carlsbad, CA) according to the manufacturer's protocol. Reactions were carried out in $20-\mu \mathrm{L}$ volumes consisting of $1 \times$ buffer, $200 \mathrm{U}$ of Moloney-murine leukemia virus reverse transcriptase, $40 \mathrm{U} / \mu \mathrm{L}$ RNase inhibitor (Roche Molecular Biochemicals, Indianapolis, IN), $5 \mu \mathrm{mol} / \mathrm{L}$ random hexamers (Life Technologies) and $5 \mu \mathrm{L}$ total RNA. Reactions were incubated in a PCR thermocycler at $25^{\circ} \mathrm{C}$ for 10 minutes, $37^{\circ}$ $\mathrm{C}$ for 50 minutes, and $70^{\circ} \mathrm{C}$ for 15 minutes and then cooled to $4^{\circ} \mathrm{C}$. After RT, samples were diluted by adding $60 \mu \mathrm{L}$ of purified water (Sigma, St. Louis, MO). Negative controls were "no mRNA," in which $5 \mu \mathrm{L}$ of RNase-free water was substituted for mRNA template in the RT reaction.

\section{Real-Time Quantitative RT-PCR}

The relative abundance of epidermal growth factor receptor (EGFR), p21, matrix metalloproteinase (MMP)-1, and vascular endothelial growth factor (VEGF) mRNA was assessed using the 5' fluorogenic nuclease assay to perform real-time quantitative PCR. EGFR, MMP-1, and VEGF were selected because they have been shown to be overexpressed at the mRNA and protein level in a large proportion of oral squamous cell carcinoma (10-13). p21 protein is also elevated in large proportion of oral dysplasias and squamous cell carcinomas but shows no mRNA overexpression $(14,15)$.

The basis for the TaqMan system is continuous measurement of PCR product accumulation using a dual-labeled fluorogenic oligonucleotide probe. On the $5^{\prime}$ terminus is a reporter dye $(\mathrm{FAM}=6$-carboxy- fluorescein), and on the 3 ' terminus is a quenching dye (TAMRA $=6$-carboxytetramethylrhodamine). The oligonucleotide sequence is homologous to a target sequence, and PCR primers encompassing the probe sequence are added. When the probe is intact, energy transfer between the two fluorophors occurs, and the quencher eliminates emission from the reporter. During the extension phase of PCR the probe is cleaved by 5 ' nuclease activity of Taq polymerase, releasing the reporter from the oligonucleotide quencher and resulting in an increase of reporter emission intensity. Intron-spanning primer and probe sequences (Table 1) either were obtained from published sequences $(4,5)$ or were designed to meet specific criteria by using Primer Express design software (PE Biosystems, Foster City, CA; 16). Primers and probes were synthesized by Integrated DNA Technologies (Coralville, IA).

The ABI 7700 Prism (PE Biosystems) uses fiber optics connected with each well in a 96-well PCR tube arrangement so as to laser excite and measure the fluorescence spectra intensity from each tube with continuous monitoring during PCR amplification. Each tube is reexamined every 8.5 seconds. Computer software examines the fluorescence intensity of reporter and quencher over the course of the amplification so as to calculate continuously the increase in normalized reporter emission intensity. This result was plotted versus time, represented by cycle number, to produce a continuous measure of PCR amplification. To provide precise quantification of initial target in each PCR reaction, the amplification plot was examined at a point during the log phase of product accumulation accomplished by assigning a fluorescence threshold above background and determining the point at which each amplification plot crosses the threshold (defined as the threshold cycle number, or Ct). Differences in $\mathrm{Ct}$ were used to quantify the relative

\section{Prohibited}

TABLE 1. Sequences of PCR Primers and Fluorogenic Probes Used in Quantitative PCR

\begin{tabular}{|c|c|c|c|}
\hline $\begin{array}{c}\text { Gene } \\
\text { (Reference No.) }\end{array}$ & Primer/Probe & Sequence & $\begin{array}{l}\text { Amplicon Size } \\
\text { (bp) }\end{array}$ \\
\hline \multirow[t]{3}{*}{$\beta$-Gus (5) } & $\beta$-Gus-F & CTCATTTGGAATTTTGCCGATT & 81 \\
\hline & $\beta$-Gus-R & CCGAGTGAAGATCCCCTTTTTA & \\
\hline & $\beta$-Gus-probe & FAM-TGAACAGTCACCGACGAGAGTGCTGG & \\
\hline \multirow[t]{3}{*}{ EGFR (5) } & EGFR-F & CGCAAGTGTAAGAAGTGCGAA & 93 \\
\hline & EGFR-R & CGTAGCATTTATGGAGAGTGAGTCT & \\
\hline & EGFR-probe & FAM-CCTTGCCGCAAAGTGTGTAACGGAAT & \\
\hline \multirow[t]{3}{*}{ MMP-1 } & MMP-1-F & GAGGGTCAAGCAGACATCATGA & 52 \\
\hline & MMP-1-R & CAAGATTTCCTCCAGGTCCATC & \\
\hline & MMP-1-probe & FAM-TGTCAGGGGAGATCATCGGGACAA & \\
\hline \multirow[t]{3}{*}{ p21 (4) } & $\mathrm{p} 21-\mathrm{F}$ & CTGGAGACTCTCAGGGTCGAA & 66 \\
\hline & $\mathrm{p} 21-\mathrm{R}$ & GGCGTTTGGAGTGGTAGAAATCT & \\
\hline & p21-probe & FAM-ACGGCGGCAGACCAGCATGA & \\
\hline \multirow[t]{3}{*}{ VEGF (5) } & VEGF-F & СТСТАССТССАССАТGССАAG & 90 \\
\hline & VEGF-R & AGACATCCATGAACTTCACCACTTC & \\
\hline & VEGF-probe & FAM-TGGCAGAAGGAGGAGGGCAGAATCA & \\
\hline
\end{tabular}

All probes were labeled with 3'TAMRA (6-carboxytetramethylrhodamine) quencher dye. PCR, polymerase chain reaction; FAM = 6-carboxyfluorescein; EGFR, epidermal growth factor receptor; MMP-1, matrix metalloproteinase; VEGF, vascular endothelial growth factor. 
amount of PCR target contained within each tube. Assuming that each reaction functions at $100 \%$ PCR efficiency, a difference of one Ct represents a 2-fold difference in the amount of starting template.

Quantitative RT-PCR was performed in triplicate $50-\mu \mathrm{L}$ reaction volumes consisting of $1 \times$ PCR buffer (PE Biosystems), $5.5 \mathrm{mmol} / \mathrm{L} \mathrm{MgCl}_{2}, 0.5 \mu \mathrm{M}$ of forward and reverse primers, $0.2 \mu \mathrm{M}$ of probe, 0.025 $\mathrm{U} / \mu \mathrm{L}$ AmpliTaq Gold (PE Biosystems), and $5 \mu \mathrm{L}$ of the appropriate RT reaction. Two-step PCR cycling was carried out as follows: $95^{\circ} \mathrm{C}$ for 12 minutes (1 cycle), $95^{\circ} \mathrm{C}$ for 15 seconds, $60^{\circ} \mathrm{C}$ for 1 minute ( 40 cycles). At the end of the PCR, baseline and threshold values were established using the ABI 7700 Prism software, and the Ct values were exported to Microsoft Excel (Microsoft Corp., Redmond, WA) for analysis.

\section{Calculation of Relative Expression}

Relative expression of mRNA was calculated using the comparative $\mathrm{Ct}$ method previously described $(5,17)$. This method of analysis was selected because the slopes of the standard curve for each marker (Fig. 1) were not significantly different across a range of input RNA, thus differences in relative abundance for low- or high-quantity RNA species would not distort the analysis. Moreover, absolute Ct values for each sample were found to all lie within the range of $\mathrm{Ct}$ values used for standard curve generation.

Analysis was carried out using the sequence detection software supplied with the ABI 7700 (PE Biosystems). This software/calculates the Ct for each reaction and uses it to quantify the amount of starting template in the reaction. All data were controlled for quantity of input RNA by perform-

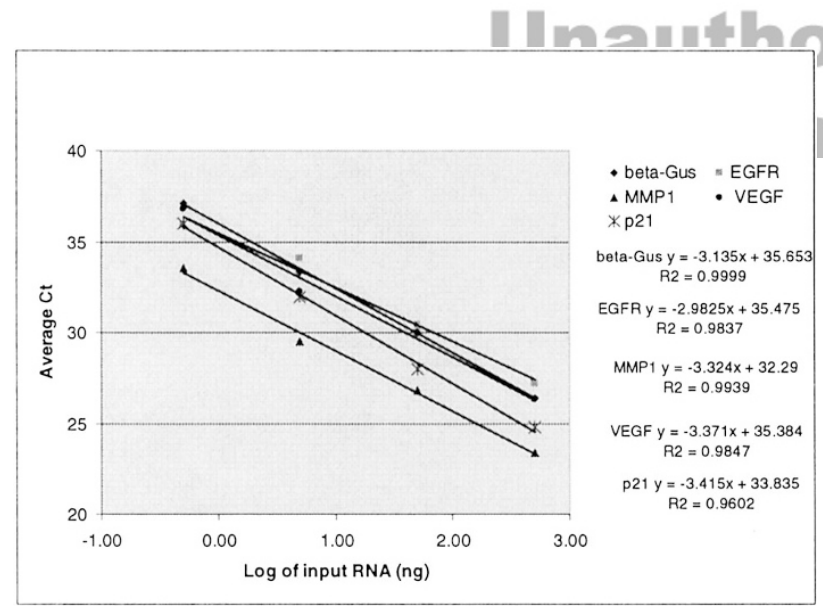

FIGURE 1. The logarithm of the input RNA amount from the same sample plotted versus the threshold cycle (Ct) monitored during TaqMan quantitative RT-PCR. Amplification efficiency of $\beta$ - $N$-acetylglucosaminidase, epidermal growth factor receptor, matrix metalloproteinase, vascular endothelial growth factor, and p21 genes are shown as regression lines. All points represent the mean of duplicate PCR amplifications. Error bars are too small to be shown. ing measurements on an endogenous reference gene $\beta$ - $N$-acetyl-glucuronidase $(\beta-\mathrm{Gus} ; 5,18)$. The Ct values for each set of three reactions were averaged for all subsequent calculations. A difference in $\mathrm{Ct}$ values $(\Delta \mathrm{Ct})$ was calculated for each marker by taking the mean $\mathrm{Ct}$ of triplicate tubes and subtracting the mean $\mathrm{Ct}$ of triplicate tubes for $\beta$-Gus. To calculate the relative RNA of a test sample compared with normal RNA, a $\Delta$ Ct was determined as follows:

$$
\Delta \mathrm{Ct}=\mathrm{Ct}(\mathrm{EGFR})-\mathrm{Ct}(\beta-\mathrm{Gus})
$$

From this value, a relative RNA expression can be calculated using the following formula:

$$
\text { Relative RNA }=2^{-\Delta \mathrm{Ct}}
$$

Using this calculation, we defined no change in relative RNA expression as when this value was equal to 1 ; overexpression, when it was $>1$; and under expression, when it was $<1$. For simplicity, PCR efficiencies were assumed to be $100 \%$. PCR efficiencies were measured as previously described(16) and were found to be $>95 \%$ (Fig.1); therefore, this assumption introduced minimal error into the calculation.

\section{Immunohistochemistry}

Immunohistochemistry was performed as previously described (19) to determine the expression levels of EGFR, MMP-1, p21, and VEGF proteins. Briefly, $5-\mu \mathrm{m}$ sections were cut and mounted on adherent glass slides (Fisher Scientific, Houston, TX). Sections were dewaxed in xylene and rehydrated in graded ethanols. Endogenous peroxidase activity was blocked by immersion in $0.5 \%$ methanolic peroxide for 15 minutes, followed by two washes in $1 \times$ phosphate buffered saline (PBS) for 5 minutes each. Immunoreactivity of the target antigen was enhanced using pressurized heat antigen retrieval using $0.6 \mathrm{~m}$ sodium citrate buffer and heating to $100^{\circ} \mathrm{C}$ for 15 minutes (20). The sections were then removed, quenched in deionized water, and rinsed in PBS. The sections were then incubated for 1 hour at room temperature with primary antibodies to EGFR, MMP-1, p21, or VEGF diluted to 1:100 in PBS. Monoclonal anti-EGFR (Clone 528) was obtained from Oncogene Research Products (Cambridge, MA) and recognizes the external domain of the epitope. Monoclonal anti-MMP-1 (Clone 411E5) was obtained from Oncogene Research Products and recognizes both latent $(57 / 52 \mathrm{kDa})$ and active $(46 / 42 \mathrm{kDa})$ forms of MMP-1. Monoclonal anti-p21 (Clone EA-10) was obtained from Biogenex (San Ramon, CA). Polyclonal anti-VEGF (Clone A-20) recognizes 165, 109, and 121 amino acid isoforms and was obtained from Santa Cruz Bio- 
technology (Santa Cruz, CA). Incubation was followed by two washes in PBS and then application of a biotinylated secondary antibody, washed twice in PBS followed by the application of preformed avidin-biotin complex (DAKO Corp., Carpinteria, CA) for 30 minutes (21). The bound complexes were visualized by the application of a $0.05 \%$ solution of 3-amino-9-ethylcarbozole (Sigma Corp.) containing $0.3 \%$ hydrogen peroxide as a substrate. After incubation, the sections were washed and then lightly counterstained in hematoxylin and coverslipped.

\section{Quantification of Immunohistochemistry}

Immunohistochemical staining was scored by examining sections at $40 \times$ objective to assess the proportion of cells showing membrane (EGFR), cytoplasmic (MMP-1, VEGF), or nuclear (p21) expression and with confirmation of positive staining done at $100 \times$ objective. The percentage of positive cells was scored using the method of Xia et al. (22) as follows: $3,>50 \%$ of cells staining $+; 2,25$ to $49 \%$ of cells staining $+; 1,5$ to $24 \%$ of cells staining $+; 0$ : negative or $<5 \%$ of cells staining + .

\section{RESULTS}

\section{RNA Extraction}

We were able to isolate mRNA from $9 / 9(100 \%)$ fresh and $36 / 36(100 \%)$ tissue biopsies of normal, epithelial dysplasia and squamous cell carcinoma fixed for differing times. In addition, we were also successfully able to extract RNA and amplify cDNA from 15/15 (100\%) routinely processed oral squamous cell carcinoma obtained from the tissue bank. carcinoma groups, mean mRNA expression levels for MMP-1, EGFR, p21, and VEGF were elevated. By immunohistochemistry, overexpressed $(\geq 2+)$ EGFR protein was seen in none of the normal epithelial controls, 2 of 3 dysplasias, and 3 of 4 squamous cell carcinomas. Two carcinomas showed overexpressed $(\geq 2+)$ p21 protein, and two squamous cell carcinoma showed MMP-1 protein overexpression $(\geq 1+)$. VEGF was overexpressed $(\geq 2+)$ by all oral squamous cell carcinomas.

\section{Effect of Formalin Fixation Time on Quantitative RT-PCR}

Results of fixation time are summarized in Table 3 , where values have been normalized to the fresh tissue (time $=0 \mathrm{~h}$ ). Values represent the relative change in mRNA expression in comparison to the expression levels in fresh, unfixed tissues. Therefore, a value of 1 indicates no change in expression between the fixed specimens and fresh tissue at that time point. These results are summarized graphically in Figure 2. In general, prolonged formalin fixation $(>48 \mathrm{~h}$ ) had a detrimental effect on the amplification efficiency of PCR. These effects were variable and depended on the specific probe and the duration of fixation. For all markers studied, the results at 24 hours were similar to the case in fresh tissues. However, by 48 hours of fixation, both MMP-1 and VEGF expression appeared to be markedly increased compared with that seen in the fresh tissues. p21 showed markedly altered gene expression, compared with results from fresh tissues, at 72 hours. By contrast, EGFR showed relatively robust results at all time points up to 1 week. Signal was not detected for any marker in negative controls $(\mathrm{Ct}=40)$.

\section{Quantitative mRNA Analysis in Fresh Tissue}

By quantitative RT-PCR, we found that both cases of normal epithelium did not show overexpression of EGFR, MMP-1, or VEGF but that there was a mean 2-fold relative increase in p21 mRNA (Table 2). For the dysplasia and squamous cell
Quantitative mRNA Analysis in Archival

\section{Tumor Tissues}

To further examine the suitability of the quantitative RT-PCR assay, we compared mRNA levels to protein levels in 15 archived, formalin-fixed, paraffin-embedded oral squamous cell carcinoma

TABLE 2. Mean Relative mRNA Expression Levels of MMP-1, EGFR, p21, and VEGF in Fresh Tissue Biopsies of Normal, Dysplastic and Neoplastic Oral Epithelium

\begin{tabular}{|c|c|c|c|c|c|c|c|c|c|}
\hline \multirow{3}{*}{ Factor } & \multirow{2}{*}{\multicolumn{2}{|c|}{$\begin{array}{c}\text { Normal Epithelium } \\
(N=2) \\
\text { Sample No. }\end{array}$}} & \multirow{2}{*}{\multicolumn{3}{|c|}{$\begin{array}{l}\text { Dysplasia Epithelium } \\
\qquad(N=3) \\
\text { Sample No. }\end{array}$}} & \multicolumn{4}{|c|}{$\begin{array}{l}\text { Squamous Cell Carcinoma Epithelium } \\
\qquad(N=4)\end{array}$} \\
\hline & & & & & & \multicolumn{4}{|c|}{ Sample No. } \\
\hline & 1 & 2 & 1 & 2 & 3 & 1 & 2 & 3 & 4 \\
\hline MMP-1 & 0.13 & 0.02 & 0.07 & 8.96 & 1.84 & 2.07 & 0.66 & 24.50 & 5.10 \\
\hline EGFR & 0.20 & 0.54 & 0.93 & 4.58 & 3.93 & 0.39 & 1.61 & 31.30 & 3.61 \\
\hline $\mathrm{p} 21$ & 4.45 & 0.08 & 0.31 & 16.37 & 4.71 & 16.02 & 0.60 & 0.66 & 0.31 \\
\hline VEGF & 1.00 & 0.02 & 0.44 & 88.44 & 0.01 & 10.29 & 0.22 & 151.17 & 3.54 \\
\hline
\end{tabular}

All data points represent mean of triplicate runs. All points were measured relative to $\beta$-Gus. MMP-1, matrix metalloproteinase; EGFR, epidermal growth factor receptor; VEGF, vascular endothelial growth factor. 
TABLE 3. Summary of Changes in mRNA Expression Compared with Fresh Tissue after Differing Intervals of Fixation in $10 \%$ Buffered Formalin

\begin{tabular}{|c|c|c|c|c|}
\hline Fixation Time ${ }^{a}$ & Normal $(N=2)$ & Dysplasia $(N=3)$ & Carcinoma $(N=4)$ & Mean \\
\hline & & & & \\
\hline $0 \mathrm{~h}$ & 1.00 & 1.00 & 1.00 & 1.00 \\
\hline $24 \mathrm{~h}$ & 0.52 & 2.27 & 1.60 & 1.47 \\
\hline $48 \mathrm{~h}$ & 0.51 & 9.29 & 4.14 & 4.65 \\
\hline $72 \mathrm{~h}$ & 4.02 & 4.54 & 13.56 & 7.37 \\
\hline \multirow[t]{2}{*}{1 week } & 8.92 & 3.07 & 1.80 & 4.60 \\
\hline & \multicolumn{4}{|c|}{ EGFR } \\
\hline $0 \mathrm{~h}$ & 1.00 & 1.00 & 1.00 & 1.00 \\
\hline $24 \mathrm{~h}$ & 1.50 & 0.78 & 0.65 & 0.98 \\
\hline $48 \mathrm{~h}$ & 1.43 & 0.52 & 0.76 & 0.91 \\
\hline $72 \mathrm{~h}$ & 1.82 & 0.49 & 1.01 & 1.11 \\
\hline \multirow[t]{2}{*}{1 week } & 1.38 & 0.62 & 0.98 & 0.99 \\
\hline & \multicolumn{4}{|c|}{$\mathrm{p} 21$} \\
\hline $0 \mathrm{~h}$ & 1.00 & 1.00 & 1.00 & 1.00 \\
\hline $24 \mathrm{~h}$ & 0.56 & 1.22 & 1.04 & 0.94 \\
\hline $48 \mathrm{~h}$ & 1.13 & 0.69 & 0.91 & 0.91 \\
\hline $72 \mathrm{~h}$ & 6.01 & 0.73 & 0.87 & 2.54 \\
\hline \multirow[t]{2}{*}{1 week } & 0.47 & 0.75 & 0.80 & 0.68 \\
\hline & \multicolumn{4}{|c|}{ VEGF } \\
\hline $0 \mathrm{~h}$ & 1.00 & 1.00 & 1.00 & 1.00 \\
\hline $24 \mathrm{~h}$ & 0.86 & 2.16 & 4.98 & 2.67 \\
\hline $48 \mathrm{~h}$ & 3.31 & 2.23 & 13.89 & 6.48 \\
\hline $72 \mathrm{~h}$ & 10.21 & 0.60 & 36.44 & 15.75 \\
\hline 1 week & 0.19 & 1.31 & 10.74 & 4.08 \\
\hline
\end{tabular}

Results are the mean of triplicate runs. All points were measured relative to $\beta$-Gus and normalized to fresh tissue RNA. No change $=1$. MMP-1, matrix metalloproteinase; EGFR, epidermal growth factor receptor; VEGF, vascular endothelial growth factor.

${ }^{\text {a }} 0 \mathrm{~h}=$ fresh, unfixed.

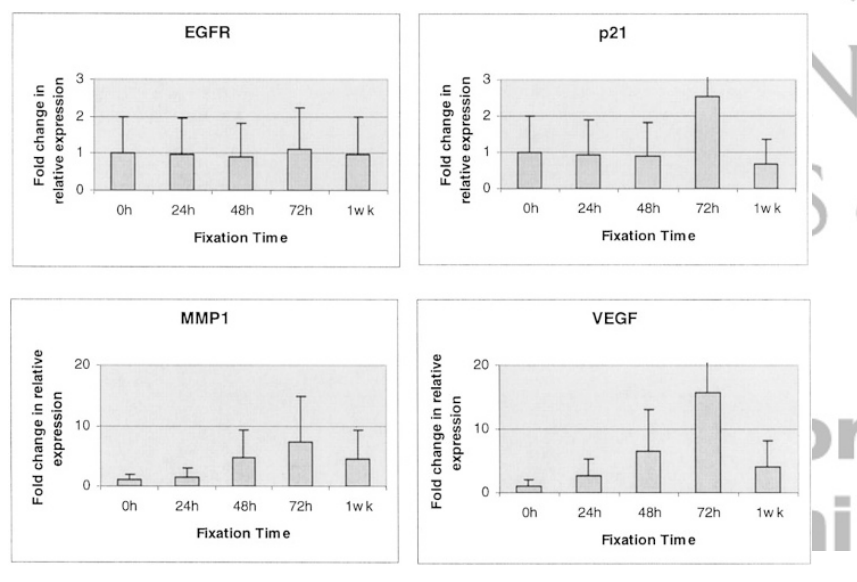

FIGURE 2. Effect of differing fixation times on quantification of epidermal growth factor receptor, p21, matrix metalloproteinase, and vascular endothelial growth factor mRNA species in oral tissues $(n=9)$. Solid bars indicate the mean change in relative expression for each marker in the same tissues fixed for differing intervals after normalization to the expression in unfixed, frozen tissue $(0 \mathrm{~h})$; no change $=1$. Error bars represent standard deviations. All points were measured relative to $\beta$ - $N$-acetyl-glucosaminidase.

using the markers EGFR, MMP-1, p21, and VEGF. Results are shown in Table 4 and summarized in Table 5. We were able to isolate mRNA, transcribe to cDNA, and amplify by PCR in all $(15 / 15 ; 100 \%)$ cases. RNA signal was not detected for any marker in negative controls.

We found EGFR mRNA overexpression (relative expression $>1$ ) in $14 / 15(93 \%)$ oral squamous cell carcinoma, and one case showed reduced EGFR expression (relative expression $<1$ ). Overexpression of mRNA ranged from 1.3-fold to 9-fold. EGFR protein overexpression $(\geq 2+)$ was identified in $10 / 15$ $67 \%)$ tumors. In normal epithelium, EGFR protein was expressed only in basal keratinocytes, accounting for approximately $5 \%$ of the total keratinocyte population.

For MMP-1, there was mRNA overexpression in $14 / 15$ (93\%) oral squamous cell carcinoma and protein overexpression in the same 14/15 (93\%) cases. Because MMP-1 protein was not seen in normal epithelial controls (data not shown), we interpreted MMP-1 protein levels $\geq 1+(\geq 5 \%$ positive cells) as abnormally expressed (23). Similarly for VEGF, 14/15 (93\%) cases showed increased mRNA, and 11/15 (73\%) cases showed elevated protein levels. VEGF protein was weakly expressed in $<5 \%$ of normal keratinocytes, and therefore we interpreted overexpression when there was $\geq 2+$ staining. p21 mRNA was underexpressed in all cases, but by immunohistochemistry all but one tumor showed overexpressed protein.

All tumors showing overexpressed EGFR, MMP-1, or VEGF protein showed increased mRNA by real time-PCR. By contrast, no case showed p21 mRNA overexpression, and all but one case had elevated protein levels by immunohistochemistry. 
TABLE 4. Comparison of mRNA Expression Levels Determined by Quantitative RT-PCR Assay and Protein Expression by Immunohistochemical Analysis in Formalin-Fixed, Paraffin-Embedded Tissue Sections of Oral Squamous Cell Carcinoma

\begin{tabular}{|c|c|c|c|c|c|c|c|c|}
\hline \multirow{3}{*}{ Specimen No. } & \multicolumn{8}{|c|}{ Marker $^{\mathrm{a}}$} \\
\hline & \multicolumn{2}{|c|}{ EGFR } & \multicolumn{2}{|c|}{ MMP-1 } & \multicolumn{2}{|c|}{$\mathrm{p} 21$} & \multicolumn{2}{|c|}{ VEGF } \\
\hline & mRNA & Protein & mRNA & Protein & mRNA & Protein & mRNA & Protein \\
\hline 1 & 3.24 & 3 & 12.52 & 2 & 0.37 & 3 & 3.85 & 3 \\
\hline 2 & 9.00 & 3 & 4.37 & 0 & 0.06 & 3 & 8.82 & 3 \\
\hline 3 & 1.29 & 2 & 15.49 & 1 & 0.41 & 3 & 4.76 & 3 \\
\hline 4 & 1.92 & 1 & 5.40 & 1 & 1.31 & 2 & 1.69 & 1 \\
\hline 5 & 4.56 & 3 & 0.43 & 0 & 0.58 & 3 & 7.36 & 3 \\
\hline 6 & 1.09 & 3 & 9.87 & 3 & 0.12 & 3 & 1.40 & 1 \\
\hline 7 & 2.63 & 3 & 9.29 & 3 & 0.38 & 1 & 4.59 & 3 \\
\hline 8 & 1.80 & 1 & 58.89 & 3 & 6.84 & 3 & 4.92 & 3 \\
\hline 9 & 3.16 & 3 & 87.22 & 3 & 0.60 & 3 & 17.75 & 3 \\
\hline 10 & 2.39 & 1 & 39.85 & 3 & 0.72 & 3 & 6.29 & 3 \\
\hline 11 & 2.38 & 2 & 10.36 & 3 & 0.90 & 3 & 6.50 & 3 \\
\hline 12 & 0.81 & 0 & 7.97 & 3 & 0.31 & 3 & 1.23 & 1 \\
\hline 13 & 4.18 & 3 & 11.60 & 1 & 0.38 & 3 & 10.08 & 3 \\
\hline 14 & 4.03 & 3 & 9.25 & 1 & 0.12 & 2 & 13.83 & 3 \\
\hline 15 & 2.34 & 2 & 4.73 & 3 & 0.64 & 3 & 0.93 & 1 \\
\hline
\end{tabular}

All samples fixed for 24 hours; results are the mean of triplicate runs. EGFR, epidermal growth factor receptor; MMP-1, matrix metalloproteinase; VEGF, vascular endothelial growth factor.

${ }^{a}$ Percentage of positive cells for protein was scored as follows: $3,>50 \%$ of cells $+; 2,25$ to $49 \%+; 1,5$ to $24 \%+; 0$, negative or $<5 \%$ of cells + .

TABLE 5. Summary of mRNA Expression Levels Determined by Quantitative RT-PCR Assay and Protein Expression by Immunohistochemical Analysis in Formalin-Fixed, Paraffin-Embedded Tissue Sections of Oral Squamous Cell Carcinoma

\begin{tabular}{lcc}
\hline Marker & $\begin{array}{c}\text { mRNA } \\
\text { Overexpression, }\end{array}{ }^{\mathrm{a}} n(\%)$ & $\begin{array}{c}\text { Protein } \\
\text { Overexpression, }\end{array}{ }^{\mathrm{b}} n(\%)$ \\
\hline EGFR & $13(87)$ & $10(67)$ \\
MMP-1 & $14(93)$ & $14(93)$ \\
p21 & $2(13)$ & $14(93)$ \\
VEGF & $14(93)$ & $11(73)$ \\
\hline
\end{tabular}

EGFR, epidermal growth factor receptor; MMP-1, matrix metalloproteinase; VEGF, vascular endothelial growth factor. $>1$.

mRNA overexpression defined as cases showing relative expression

b Based on expression in normal epithelium, overexpression of EGFR, p21 and VEGF proteins was defined as cases having a score of $2+$ or greater $(>25 \%$ positive cells). For MMP1 protein, there was no expression in normal epithelium so overexpression in tumors was defined as cases having a score of $1+$ or greater $(>5 \%$ positive cells).

\section{DISCUSSION}

The purpose of this study was to examine the effect of prolonged formalin fixation on quantitative RT-PCR analysis. We found that mRNA can be reliably extracted from formalin-fixed, paraffinembedded tissue sections but that prolonged formalin fixation $(>48 \mathrm{~h}$ ) has a detrimental effect on quantitative RT-PCR that is marker specific.

It is well established that DNA can be extracted from formalin-fixed, paraffin-embedded tissue sections and subjected to molecular analysis $(24,25)$. In the study of cancer, DNA analysis has proven useful for the study of molecular changes in tumors and for the identification of potential pathogens that may cause specific neoplasms (26-28). The molecular analysis of DNA extracted from paraffin sections is also a frequent component in the rou- tine assessment of many types of lymphomas (29). However, there are a number of important biological limitations when studying DNA from tumors, and hence the analysis of transcriptional events, providing a dynamic assessment of the cells, is more desirable.

In the past, it was thought that RNA extracted from paraffin tissue sections was too degraded to permit analysis (30). Many early attempts to extract RNA from formalin-fixed, paraffin-embedded tissues yielded low quantity and poor-quality material. Technical problems to overcome include RNA fragmentation, formalin-induced protein crosslinking, the addition of monomethyl groups to nucleotides, dimerization of adenine which interferes with subsequent PCR, ubiquitous RNase enzymes, and paraffin interference with RNA extraction by guanidinium hydrochloride $(1,31)$.

More recent studies have shown that RNA can be extracted successfully from formalin-fixed paraffinembedded tissue section and used for cDNA template generation and subsequent PCR $(4,5,32,33)$. The most effective isolation methods involve the use of a concentrated proteinase K digestion step to solubilize tissue proteins and reverse monomethyl nucleotide modification to RNA $(24,30)$. Although these methods can yield RNA suitable for PCR amplification and analysis, the effect of prolonged formalin fixation has not been well studied. Previous studies that have examined this issue in a controlled manner have used fixation times of $\leq 24$ hours $(3,5,24,34,35)$. Although this duration may be suitable for small tissues obtained in some hospital settings, it is likely shorter than those typically used for larger specimens or those obtained in outpatient settings or in mail-in biopsy services. 
We used a modified proteinase $\mathrm{K}$ digestion protocol with a phenol extraction step for the isolation of RNA from formalin-fixed, paraffin-embedded tissue sections (4). We show that isolation of RNA and conversion to cDNA was possible for all formalinfixed specimens, irrespective of fixation time. This finding is in agreement with those of others who have also shown reliable isolation of RNA from paraffin sections using proteinase $\mathrm{K}$ digestion $(5,6$, $9,30,32,36)$. Significantly, by coupling our extraction method with TaqMan RT-PCR, we were able to generate reproducible quantitative data. It has been shown previously that PCR success was limited by attempts to amplify large target fragments and that best success was obtained when target amplicons were small (5). Therefore, we used primers designed to generate amplicons of $<100 \mathrm{bp}$ in size. Our results, therefore, show that the extraction of RNA, conversion to cDNA, and quantitative PCR analysis should be possible in the majority of cases using the protocol we describe here.

It is unclear why there were differences in the performance of different markers using the same study material. Both MMP-1 and VEGF showed marked alterations in their expression levels by 48 hours, in contrast to EGFR and p21, which showed more robust amplification results. One possibility may be due to differences in amplicon sizes, although this seems unlikely because all targets were $<100$ base pairs in size. Moreover, the EGFR amplicon size was the largest marker at 93 base pairs and yet performed well on all material irrespective of fixation duration. It is conceivable that results may be related to differences in mRNA sequences and the generation of secondary structures that are more susceptible to the effects of prolonged formalin-fixation. Furthermore, absolute $\mathrm{Ct}$ values were higher at 72 hours than at 1 week, suggesting that the amount of recoverable RNA was less at the earlier time point. We believe that this result is unlikely to be caused by differences in primer amplification efficiencies because the slopes of the standard curves for all markers relative to the reference gene were similar over a range of input RNA. Moreover, this is unlikely to be caused by processing because all specimens had been handled in an identical manner, apart from duration of formalin fixation. Therefore, our results suggest that although RNA yield from formalin-fixed, paraffinembedded tissue sections is high, for accurate quantitative RT-PCR it is necessary to select primers judiciously and limit fixation times to 24 hours.

We found that in all cases of oral squamous cell carcinoma in which there was protein overexpression of MMP-1, EGFR, and VEGF, there was a corresponding overexpression of mRNA, as determined by the quantitative RT-PCR assay. These results were expected because these mRNA and protein species are recognized to be overexpressed in a significant proportion of oral squamous cell carcinoma (10). Some oral squamous cell carcinomas showed high expression levels of different mRNA species (i.e., MMP-1 versus EGFR) but correspondingly low protein expression. This finding is not surprising and may be attributed to differences in translation of specific mRNA species in these tumors (37). By contrast, we found that p21 mRNA was frequently low in the oral squamous cell carcinoma but that $\mathrm{p} 21$ protein was often overexpressed. This finding is consistent with that of a previously published study comparing p21 mRNA and protein levels in oral squamous cell carcinoma (14) and supports the concept that p21 protein levels are primarily regulated by translational mechanisms through ubiquitin-mediated degradation (38). Thus, our results confirm the suitability of quantitative RT-PCR for determining relative mRNA expression in formalin-fixed, paraffin-embedded tissue sections.

\section{REFERENCES}

1. Lewis F, Maughan NJ, Smith V, Hillan K, Quirke P. Unlocking, the archive-gene expression in paraffin-embedded tissue. J Pathol 2001;195:66-71.

2. Freeman WM, Walker SJ, Vrana KE. Quantitative RT-PCR. Pitfalls and potential. Biotechniques 2002;26:112-25.

3. Foss RD, Guha-Thakurta N, Conran RM, Gutman P. Effects of fixative and fixation time on the extraction and polymerase chain reaction amplification of RNA from paraffinembedded tissue. Comparison of two housekeeping gene mRNA controls. Diagn Mol Pathol 1994;3:148-55.

4. Specht K, Richter T, Muller U, Walch A, Werner M, Hofler H. Quantitative gene expression analysis in microdissected archival formalin-fixed and paraffin-embedded tumor tissue. Am J Pathol 2001;158:419-29.

5. Godfrey TE, Kim SH, Chavira M, Ruff DW, Warren RS, Gray JW, et al. Quantitative mRNA expression analysis from formalin-fixed, paraffin-embedded tissues using $5^{\prime}$ nuclease quantitative reverse transcription-polymerase chain reaction. J Mol Diagn 2000;2:84-91.

6. Tyrrell L, Elias J, Longley J. Detection of specific mRNAs in routinely processed dermatopathology specimens. Am J Dermatopathol 1995;17:476-83.

7. Jackson DP, Quirke P, Lewis F, Boylston AW, Sloan JM, Robertson D, et al. Detection of measles virus RNA in paraffin-embedded tissue. Lancet 1989;1:1391.

8. Stanta G, Bonin S. RNA quantitative analysis from fixed and paraffin-embedded tissues: membrane hybridization and capillary electrophoresis. Biotechniques 1998;24:271-6.

9. Finke J, Fritzen R, Ternes P, Lange W, Dolken G. An improved strategy and a useful housekeeping gene for RNA analysis from formalin-fixed, paraffin-embedded tissues by PCR. Biotechniques 1993;14:448-53.

10. Grandis JR, Tweardy DJ. Elevated levels of transforming growth factor alpha and epidermal growth factor receptor messenger RNA are early markers of carcinogenesis in head and neck cancer. Cancer Res 1993;53:3579-84.

11. Partridge M, Gullick WJ, Langdon JD, Sherriff M. Expression of epidermal growth factor receptor on oral squamous cell carcinoma. Br J Oral Maxillofac Surg 1988;26:381-9.

12. Alevizos I, Mahadevappa M, Zhang X, Ohyama H, Kohno Y, Posner $\mathrm{M}$, et al. Oral cancer in vivo gene expression profiling 
assisted by laser capture microdissection and microarray analysis. Oncogene 2001;20:6196-204.

13. Maeda T, Matsumura S, Hiranuma H, Jikko A, Furukawa S, Ishida $\mathrm{T}$, et al. Expression of vascular endothelial growth factor in human oral squamous cell carcinoma: its association with tumour progression and p53 gene status. J Clin Pathol 1998;51:771-5.

14. Erber R, Klein W, Andl T, Enders C, Born AI, Conradt C, et al. Aberrant p21(CIP1/WAF1) protein accumulation in headand-neck cancer. Int J Cancer 1997;74:383-9.

15. Saunders ME, Mackenzie R, Shipman R, Fransen E, Gilbert R, Jordan RCK. Patterns of p53 gene mutations in head and neck cancer: full-length gene sequencing and results of primary radiotherapy. Clin Cancer Res 1999;5:2455-63.

16. PE Applied Biosystems. ABI Prism 7700 detection system: relative quantitation of gene expression. User bulletin 2. 36 . 2001. Norwalk, CT: 1997.

17. Ginzinger DG, Godfrey TE, Nigro J, Moore DH, Suzuki S, Pallavicini MG, et al. Measurement of DNA copy number at microsatellite loci using quantitative PCR analysis. Cancer Res 2000;60:5405-9.

18. Walker RA. The histochemistry of glycosidases in human benign and malignant breast tissue. J Pathol 1984;143:39-50.

19. Shahnavaz SA, Regezi JA, Bradley G, Dube ID, Jordan RCK. p53 gene mutations in sequential oral epithelial dysplasias and carcinomas. J Pathol 2000;190:417-22.

20. Norton AJ, Jordan S, Yeomans P. Brief, high-temperature heat denaturation (pressure cooking): a simple and effective method of antigen retrieval for routinely processed tissues. J Pathol 1994;173:371-9.

21. Hsu SM, Raine L, Fanger H. Use of avidin-biotin-peroxidase complex $(\mathrm{ABC})$ in immunoperoxidase techniques: a comparison between $\mathrm{ABC}$ and unlabeled antibody (PAP) procedures. J Histochem Cytochem 1981;29:577-80.

22. Xia W, Lau YK, Zhang HZ, Xiao FY, Johnston DA, Liu AR, et al. Combination of EGFR, HER-2/neu, and HER- 3 is a stronger predictor for the outcome of oral squamous cell carcinoma than any individual family members. Clin Cancer Res 1999;5:4164-74.

23. Sutinen M, Kainulainen T, Hurskainen T, Vesterlund E, Alexander JP, Overall CM, et al. Expression of matrix metalloproteinases (MMP-1 and -2) and their inhibitors (TIMP-1, -2 and -3 ) in oral lichen planus, dysplasia, squamous cell carcinoma and lymph node metastasis. Br J Cancer 1998;77: $2239-45$.

24. Jackson DP, Lewis FA, Taylor GR, Boylston AW, Quirke P. Tissue extraction of DNA and RNA and analysis by the polymerase chain reaction. J Clin Pathol 1990;43:499-504.

25. Jordan RCK, Diss TC, Lench NJ, Isaacson PG, Speight PM Immunoglobulin gene rearrangements in lymphoplasma cytic infiltrates of labial salivary glands in Sjogren's syndrome: a possible predictor of lymphoma development. Oral Surg Oral Med Oral Pathol 1995;79:723-9.

26. Diss TC, Pan L, Peng H, Wotherspoon A, Isaacson PG. Sources of DNA for detecting B cell monoclonality using PCR. J Clin Pathol 1994;47:493-6.

27. Marchioli CC, Love JL, Abbott LZ, Huang YQ, Remick SC, Surtento-Reodica N, et al. Prevalence of human herpesvirus 8 DNA sequences in several patient populations. J Clin Microbiol 1996;34:2635-8.

28. Schneider A, Hoyer H, Lotz B, Leistritza S, Kuhne-Heid R, Nindl I, et al. Screening for high-grade cervical intraepithelial neoplasia and cancer by testing for high-risk HPV, routine cytology or colposcopy. Int J Cancer 2000; 89:529-34.

29. Wotherspoon AC, Pan LX, Diss TC, Isaacson PG. A genotypic study of low grade B-cell lymphomas, including lymphomas of mucosa associated lymphoid tissue (MALT). J Pathol 1990; 162:135-40.

30. Krafft AE, Duncan BW, Bijwaard KE, Taubenberger JK, Lichy JH. Optimization of the isolation and amplification of RNA from formalin-fixed, paraffin-embedded tissue: the Armed Forces Institute of Pathology Experience and Literature Review. Mol Diagn 1997;2:217-30.

31. Masuda N, Ohnishi T, Kawamoto S, Monden M, Okubo K. Analysis of chemical modification of RNA from formalinfixed samples and optimization of molecular biology applications for such samples. Nucleic Acids Res 1999;27:443643.

32. Stanta G, Schneider C. RNA extracted from paraffinembedded human tissues is amenable to analysis by PCR amplification. Biotechniques 1991;11:304, 306, 308.

33. Stanta G, Bonin S, Lugli M. Quantitative RT-PCR from fixed paraffin-embedded tissues by capillary electrophoresis. Methods Mol Biol 2001;163:253-8.

34. Stanta G, Bonin S, Perin R. RNA extraction from formalinfixed and paraffin-embedded tissues. Methods Mol Biol 1998;86:23-6.

35. Mizuno T, Nagamura H, Iwamoto KS, Ito T, Fukuhara T, Tokunaga M, et al. RNA from decades-old archival tissue blocks for retrospective studies. Diagn Mol Pathol 1998;7: 202-8.

36. Rupp GM, Locker J. Purification and analysis of RNA from paraffin-embedded tissues. Biotechniques 1988;6:56-60.

37. Wong DT. TGF-alpha and oral carcinogenesis. Eur J Cancer B Oral Oncol 1993;29B:3-7.

38. Yu ZK, Gervais JL, Zhang H. Human CUL-1 associates with the SKP1/SKP2 complex and regulates p21(CIP1/WAF1) and cyclin D proteins. Proc Natl Acad Sci U S A 1998;95: $11324-9$. 